\title{
The Importance and the Role of Offer Analysis in the Labour Market
}

\author{
M. Sc. Arben Terpollari \\ Prof. Dr. Klodiana Gorica \\ Prof. As. Dr. Edmond Kadiu \\ Faculty of Economics and Agribusiness, Agricultural University of Tirana \\ Email: a_terpollari@yahoo.com
}

\author{
Doi:10.5901/ajis.2016.v5n1p265
}

\begin{abstract}
This paper addresses a current and acute problem in our country and more specifically on employment and unemployment in the county of Berat. The case of this phenomenon summarized in this paper does not stand out of the general case of unemployment or employment in our country. The study of this phenomenon is given through a detailed analysis from the primary data collected directly in this area, but also from an analysis of other data processed carefully in view of highlighting the aim and meeting the objectives of this paper. The population of the county consists and is composed in certain ratios between rural and urban areas, education, age, ratios which for a period of time have been changed both in its composition and structure. This study is not focused on the definition or on general terms such as unemployment, but it aims a deeper analysis of unemployment in form and content, making the real reflection of the unemployment rate, its level and the factors that cause it. This paper goes beyond the general analysis of that has been done so far by other alternative studies in the same area, with an emphasis on the definition and identification of these factors, how do they affect employment or unemployment, increasing or decreasing its rate and which is their impact on the influence of this phenomenon. This paper gives in details the ways or opportunities to be followed to reduce or minimize the rate of unemployment.
\end{abstract}

Keywords: Unemployment, employment, unemployment rate, determining factors, unemployment rate, aggregate supply.

\section{Material and Methods}

The realization of this study is powered by: Rating factors of labor supply in Berat. Analysis of the data referred to the Employment Strategy 2014-2020; Statistical Yearbook of the Ministry of Social Welfare and Youth and INSTAT (Albanian Institute of Statistics, Employment Office, as well as various employment programs in Berat.

\section{Results and Discussion}

The county of Berat which is composed of three districts: Berat, Skarapar and Kucovë The county of Berat which is composed of three districts; Berat and Kucova Skarapar and has an average population of 143,888 inhabitants at the county level registered in 2014 or otherwise about $5 \%$ of the total population living in the region of Albania.

Even with the changes, as a result of territorial reform carried out last year it remained almost unchanged, with the exception of municipalities merging, some of which were very small and their concentration in larger administrative units. It was composed of 16 municipalities, which by the new law were merged and remained just as very small units that have one administrator and perform few services. Currently it consists of five municipalities which are: Municipality of Kucovë, Municipality of Ura Vajgurore, Municipality of Berat, Municipality of Polican and Municipality of Corovodë.

This county is characterized by prominent features in terms of geographical expansion, terrestrial climatic conditions, infrastructure etc, which create a fairly heterogeneous environment in terms of the phenomenon of unemployment. The average height above sea level is $430 \mathrm{~m}$, it occupies an area of 937.4 square kilometers, crossed by 5 rivers, the most important one Osumi and, the average temperatures ranging from - 2 degrees to 36 degrees celcius.

Given the population dynamics or performance, we note that the average number of total population has been reduced by $0.64 \%$ from the base year of the study compared to 2014 . The county of Berat in comparison to possible trends that everyone can study from the statistical reports occupies nearly an average rate of $5 \%$ of the total population. 


\section{The Composition of the Population of the County}

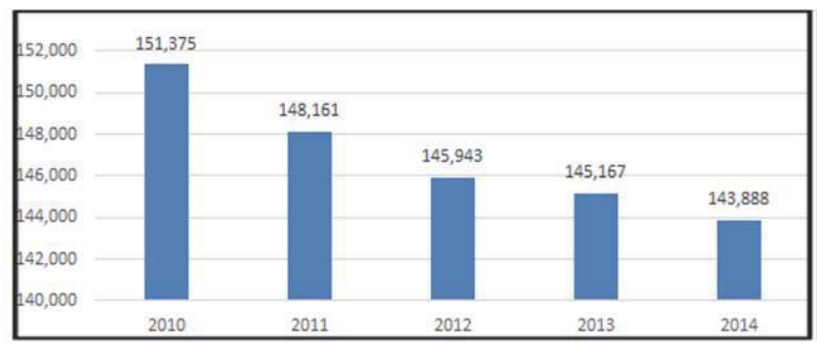

Figure 1: Berat county population, 2010-2014

Considering the above, we can analyze that the total number of population in the county of Berat it has a downward trend and it can be caused by various factors, economic and social factors such as emigration and immigration, reduction in the number of births and increase of mortality factor, etc. Furthermore, by analyzing the data, it is noted a correlated relationship between the change of the country's total population the change of the county population.

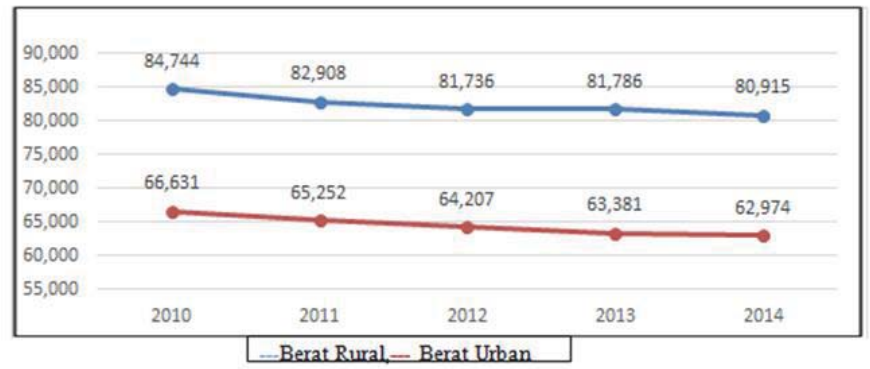

Figure 2: Urban and rural Berat county population, 2010-2014

Based on data collected from primary and secondary sources for a period of five years, we can say that we have a change in the composition of the population structure for the period under study.

This analysis is set on two levels, the educational level of the population and distribution thereof in urban and rural population. As mentioned above, the population in Berat is a decreasing function; the compositional structure of the population at county level has maintained the following ratio: $40 \%$ urban population and $60 \%$ of rural population.

In this case we note the almost stable trend of increasing the population in the county of Berat against to the total population. However, from the the observation of results we note that the percentage change of the average population of the county of Berat for the period 2010-2014 remains on an almost stable trend, while the average total population has decreased by $0.1 \%$ for the period in question.

As in the entire country, even the county of Berat in this period of study has an immigrant population movement from rural to urban areas to the extent of $2.3 \%$ from 2010 to 2014, but again the ratio of composition of the population structure remains the same. This increase in the number of urban population results from the shift of rural population towards urban centers for a better lifestyle. But this phenomenon causes the growth of the labor supply in the county's labor market, is therefore a determining factor, which increases a priori the number of unemployed workers in urban labor market.

Another aspect of the demographic analysis of the study of the area is related to the variable of gender composition, women and men. From the chart below, it is noted that the champions of the study show clear results for the first three years 2010-11-2012. The structure of the population by gender composition has been in almost equal ratios. For the years 2013-2014 this ratio differs in the format: masculine make up 51\% of the county population while feminine $49 \%$. 


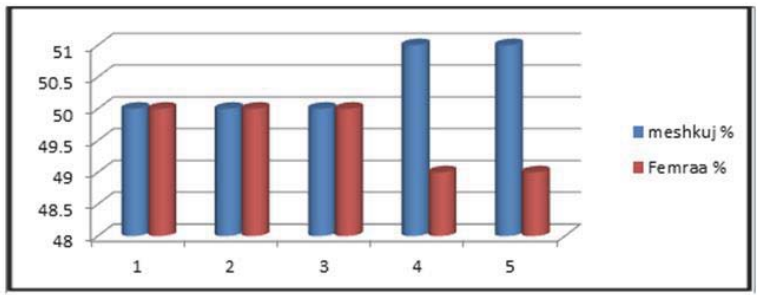

Figure 3: Composition of the population by gender

Regarding the level of education of the people in Berat we note that on average $53 \%$ of the population of the county have completed the 9 years of education and only $2.5 \%$ of the population have completed the higher education at county level, a category which has increased compared to one year before.

From the 5-year of data analysis we note that three categories of education level such as the 9-year, secondary and professional education, have had a demand function with descending and ascending amplitude (9-year education with \% higher in 2013 and the \% lower in 2014, secondary education with \% higher in 2011 and \% lower in 2014). So, for these two levels of education it is noted a declining trend for the last year of the study in 2014.

From the analysis of the level of education, only the function of the higher education at county level for this period 2010-2014 has an upward trend, which year after year grows on average by $2 \%$.

Regarding the educational level of the labor market, based on the the data of the Employment Office in the county in the job offers, education has not been a priority but the specialization in the most required professions like tailor has been significant; whereas for mass offers of paper bags and shoe production no selection criteria have been in relation to education and professionalism in this field, since a considerable part of the candidates have been trained at the companies.

The importance of analyzing the supply in the labor market in this county has been seen as a basic point for this market orientation. From the data of the Employment Office we learn that these institutions, which to some extent are responsible for policies of employment in the region, maintaining continuous contacts with entities operating in this region, we notice that during this period have been registered, i.e. have been opened a new activity, relatively few physical entities, about 31, whereas a large portion of physical entities have only changed the name of their activity, which has not affected the increase of number of employees.

In subjects with ongoing activity and mainly legal entities, which have made statements in these offices about the changes in the workforce

Job offers announced for 2013 are classified:

According to economic activities where have been announced 580 offers at employment offices.

As has been seen in this analysis, the processing industry occupies the largest number of offers announced at these offices with about $80 \%$ of total job offers, followed by the garment production, then the trade, construction, various services as well as public administration with about $3.6 \%$.

While according to profession we see that the most required occupations by the announced vacancies are: paper bags workers, folding and binding, tailoring workers of industrial sewing machines, stone slabs processing workers, service workers in trade (waiter and bartender). These are occupations for which labor market has constantly been in need as a result of the dominance of this type of businesses.

Forecast of the offer rely on experience to date and the internal needs of enterprises to meet the requirements of businesses which need workforce. A good part of employments are replacements, i.e. fulfillment of the internal needs of the entities. We should stress here that in large entities, in addition to opening new working places, the movements of employees for different reasons are numerous; this is a reason why these entities often need workforce.

Employment is a very tangible problem in recent decades in Albanian society. In the study area of the county of Berat we give a full picture regarding the employment and unemployment in the labor market. Based on the analysis of available data, this district has a number of employees of 17.123 at the end of 2014 where $48 \%$ of the total number of employees at the regional level is employed in the public sector and 52\% in the private sector. In 2014, Berat and Kucovë have the same $\%$ of employees by public and private sector in the reports $48 \%$ in the public sector and $52 \%$ in the private sector; whereas in the district of Skrapar we see a trend of demand for employment in the the private sector by $10 \%$ more than in the public sector. 
If we make a comparison of the base year 2010 and 2014 in connection with employment in private and public sector in the 3 districts, we derive a significant information that this report has changed especially for the district of Skrapar which in 2010 had a structure of employment of $84 \%$ in the public sector and only $16 \%$ in the private sector, after 5 years this ratio has been reversed by increasing the level of employment in the private sector in 2014, with 39\%.

This report has been growing for a period of 5 years because it is also related to the economic development of the area where for the period concerned there was an increase in the number of new enterprises at regional level associated with central and local policies to facilitate conducive conditions for business in the study area.

The following table provides information regarding the economic activity according to the indicators defined: companies or enterprises of Albanian and foreign origin as well as the classification of enterprises by the number of employees.

\begin{tabular}{|c|c|c|c|c|c|}
\hline 1 to 4 & 90.9 & 90.5 & 90.2 & 93.5 & 93 \\
\hline $\mathbf{5}$ to 9 & 4,8 & 4,7 & 5,2 & 2.3 & 2.6 \\
\hline $\mathbf{1 0}$ to 49 & 3.5 & 3.9 & 3.7 & 3.3 & 3.4 \\
\hline Over 50 & 0.8 & 0.9 & 0.9 & 0.9 & 1 \\
\hline
\end{tabular}

Figure 5. Berat county enterprises by number of employees

Considering the above, we notice that small or family businesses, with an average number of 4 employees, are the form of business organization which occupies the highest percentage. From the table we also note that it is an upward trend in the number of enterprises with over 50 employees, which increased by $0.2 \%$ compared to 2011 . The totality of businesses that exist in this region is of Albanian origin and on average, during 5 years of study, foreign enterprises occupy only $0.6 \%$.

Concerning the nature of the activity, we can say that in Berat we can find more service- producing enterprises (such as bars, hotels, and restaurants) than goods-producing enterprises (such as construction and fishing). At the regional level, the district of Skrapar occupies the lowest rate of $0.1 \%$ in the totality of service-producing and goodsproducing enterprises..

Regarding the analysis of the employment compared to the unemployment we can say that in 2010 , the district of Skrapar appears as the county with the highest rate of unemployment, or about $12.7 \%$ of the total number of county workforce. However, the factor of unemployment continues to be present at the end of 2014, analyzed by the reports provided by INSTAT regional offices. Districts, by area and by population size, are smaller than the center of the county, with weaker road and institutional infrastructure; they continue to have a high rate of unemployment, i.e. redundancy of labor supply, in other words a high number of unemployed people, although when compared to 2010 the number of employees has increased by 11.4 percent.

In this study we aim to convey more detailed information on the number of job-seekers according to the demographic trends of the area.

\begin{tabular}{|c|l|c|c|c|c|c|}
\hline & Emërtimi & $\mathbf{2 0 1 0}$ & $\mathbf{2 0 1 1}$ & $\mathbf{2 0 1 2}$ & $\mathbf{2 0 1 3}$ & $\mathbf{2 0 1 4}$ \\
\hline & Total number of unemployed job- seekers & 6506 & 6689 & 6402 & 6793 & 6593 \\
\hline I & By gender & \multicolumn{5}{|c|}{} \\
\hline & Female & 3395 & 3495 & 3342 & 3567 & 3176 \\
\hline & Male & 3111 & 3194 & 3060 & 3226 & 3417 \\
\hline II & By age & \multicolumn{5}{|c|}{} \\
\hline & $15-19$ & 174 & 183 & 207 & 213 & 199 \\
\hline & $20-24$ & 577 & 492 & 475 & 531 & 527 \\
\hline & $\mathbf{2 5 - 3 4}$ & 1401 & 1318 & 1180 & 1271 & 1245 \\
\hline & 35 and above & 4354 & 4696 & 4540 & 4778 & 4622 \\
\hline III & By education & \multicolumn{7}{|c|}{} \\
\hline & Up to 9 years education. & 3561 & 3565 & 3521 & 3688 & 3329 \\
\hline & Secondary education & 1521 & 1627 & 1520 & 1550 & 1520 \\
\hline & Vocational education & 1293 & 1367 & 1196 & 1407 & 1418 \\
\hline & Higher (tertiary) education & 131 & 130 & 165 & 148 & 326 \\
\hline
\end{tabular}

Figure 15: Unemployed job-seekers by gender, age and education, 2010-2014 
In relation to the demographic distribution for the period of 5 years, we note that the number of job-seekers at the regional level has been increased with an upward trend until 2012; then it becomes descending and on the above analysis this is accompanied with an increased level of employment in certain sectors or better to say mainly in the district of Skrapar, with the opening of some apparel businesses that employed mainly women.

If we continue the analysis by demographic trends for 2012 which has the highest level job seekers, $52 \%$ of them are females and $48 \%$ are males, this ratio reversed in 2014; $47 \%$ of females (thus we have a reduction of $5 \%$ of labor demand for females) and $53 \%$ of males. Regarding the age group of job-seekers for 2012 , we can say that the age group over 35 years occupies the bulk of job-seekers, about 70\%, and this ratio stands almost even at the end of 2014. In the first age group, from 15 years old to 19 and over 35, unemployment is more evident, as it is related to several reasons such as: few specializations, being still in school, few trainings, lack of willingness for work, etc. The age group from 20 to 34 years old is the most favored, where labor supply is lower and we can say that it is the most privileged age to be employed. Whereas regarding the component of educational attainment, job seekers who have completed the 9-years education occupy nearly $54 \%$ of the total number of job-seekers in 2012. Compared to 2014, this segment of analysis and age over 35 years continues to be in high levels. From such an analysis we can draw the conclusion that the economic development of the economy as a whole, but also of the regional economy has pushed the demand for professional growth and education of job-seekers, furthermore reducing the number of unemployed people, the number of women has been declining, even due to the policies that the central government has pursued to promote employment of this category in the area and especially the inward processing, with the opening of several enterprises for the production of shoes and clothes.

In our opinion, very significant in this paper is the definition of the role and responsibilities of both levels of government in relation to businesses and enterprises of the area being studied. In view of the classification and assessments of economic, social, and political fields and directions, in view of performance improvement and faster development of business / enterprises in the study area, with the main purpose of employment assessment.

The main direction of economic character which is considered as very important by business area is the tax burden and the intervention in the tax system. Economic, social and political factors are assessed as relatively significant according to the following directions: infrastructure, law enforcement, stimulating production and exports, the fight against corruption and crime, fight against nepotism, availability of specialized workforce, the cost of work, and transparency in public procurement. Businesses assessed that less important factors are represented by the following directions: EU membership, transparency, productivity and motivation of employees, as well as academic education.

Finally, we can say that: the study of factors that influence and determine the employment aggregate rate in Berat, and the core factors of the causes of unemployment determining its level, indicate that the labor market and the success of their efforts for the effective and sustainable employment, is affected by the action and interaction of various factors. The following may be listed as the most significant among them:

a) macroeconomic factors associated with aggregate demand;

b) demographic factors regarding size, quality and structural characteristics in terms of age and gender of the active labor force;

c) cultural and professional factors associated with products derived from the education system;

d) institutional factors relating to the policies, strategies, action plans.

\section{Conclusions}

$>$ In the county of Berat, economic-financial instruments, jurisdiction of both levels of government, central and local that results to be decisive in the economic activity of enterprises and consequently on unemployment reduction.

$>$ Employment in the area assessed the existence of the factors which have caused the level of unemployment resulted to be influenced from an array of factors.

$>$ Employment in Berat is evident that dominates in the private sector as a result of the dominance of the nature of service business and mainly hospitality service.

$>$ By the very nature of the the county extension, we note that a number of sectors are of seasonal nature, as a result, the employment is seasonal.

$>$ A major problem in Berat was the data keeping regarding employment and unemployment in the employment offices in the districts and county.

$>$ The biggest number of for unemployed people in Berat is the age of students and those over 35 years; as a 
result, unemployment in this age group is more evident.

$>$ People with low educational level encounter considerable problems in the labor market. There is a concentration of people with minimal education or no education in the informal sector. The level of education is closely linked to the level of income. For this reason I recommend that measures should be taken necessary to expand access to education and their vocational training. In the future, due to the urbanization of the economy, the development of human capital shall attain an even greater importance

$>$ In the framework of policies and programs formulated by the government, it should be evaluated specifically the role and contribution of women in economic and social developments in the labor market.

\section{References}

INSTAT 2014, Tirana Institute of Statistics

The Ministry of Social Welfare and Youth: National Strategy for Employment and Skills 2014-2020

Bank of Albania, Labor sector statistics, Time series 22, 2.

The Ministry the Finance of Albania, data for the year 2014

National Employment Service.

Employment Office in Berat

Directorate General of Taxation in Berat

Regional Directorate of Statistics in Berat, http://www.sociale.gov.al /al/dokumente/strategji

Law No. 7995, dated 20.09.1995 "On employment promotion" as amended by Law nr.9570,

Law nr.9374, dated 21.04.2005 "On state aid". 